\title{
The Effect of Air Throttle on Combustion Process and Emission Formation in Marine Lean-Burn Gas Engines
}

\author{
Sadi Tavakoli ${ }^{1,2}$, Jesper Schramm ${ }^{2}$, Eilif Pedersen ${ }^{1}$ \\ ${ }^{1}$ Department of Marine Technology, Norwegian University of Science and Technology \\ Trondheim, Norway \\ Sadi.tavakoli@ntnu.no; eilif.pedersen@ntnu.no \\ ${ }^{2}$ Department of Mechanical engineering, Technical University of Denmark \\ Copenhagen, Denmark \\ js@mek.dtu.dk
}

\begin{abstract}
Enhancing the marine propulsion system's performance is one of the crucial issues that has received noteworthy attention due to the current strict emission legislation. A fundamental improvement without an additional after-treatment system is employing natural gas fuel in lean-burn combustion. Lean combustion may improve the thermal efficiency in a stable condition, but a real ship works in a time-varying inflow on the propeller, and the engine must afford high-efficiency combustion against the fluctuating load. Stable combustion in a lean-burn marine gas engine is guaranteed by installing controllers on the air and the fuel pipes to regulate airfuel ratio and engine speed.

The present study aimed to investigate the influence of adding an air throttle during the engine's lower loads and its effectiveness during a time-varying load. A thermodynamics model of spark ignition engine with an imposed constant and transient load is presented. The results revealed that using a throttle in the lower loads may improve the engine fuel consumption and emission formation during steady-state, but, in transient condition, it showed a negligible impact on the brake specific fuel consumption and unburned hydrocarbon emission formation.
\end{abstract}

Keywords: Natural gas engine, Dynamic load, Marine propulsion system, Throttle valve

\section{Introduction}

Global warming due to the emissions of greenhouse gases poses a severe warning. In order to restrict this problem, a rapid decline in the emission compounds is needed, as agreed in the Paris Agreement [1]. Emission from internal combustion engines is of significant concern because of their substantial negative consequences on the local climate and human health. Unburned hydrocarbons $(\mathrm{HC})$, carbon monoxide $(\mathrm{CO})$, nitrogen oxides $\left(\mathrm{NO}_{\mathrm{X}}\right)$, and particulate matter $(\mathrm{PM})$ are the most destructive compounds. Moreover, the shipping industry's propulsion system plays a notable role in releasing hazardous emissions such as NOx and SOx [2-3]. LNG's utilization as the primary fuel of a lean-burn spark-ignition engine is one of the most promising solutions [4]. The lean-burn spark-ignition gas engine is Otto cycle theory working with an excess air ratio in the scale of lambda 2. This excess air reduces the engine components' thermal load during the combustion phenomenon and creates a steep decline in the NOx compound [5].

In contrast to the lean combustion's earlier advantages, however, the emitted methane from the primary combustion due to incomplete combustion is considerable. This compound showed a global warming potential 28 times higher than $\mathrm{CO}_{2}$ in 100 years time scale [6]. Thus, research and industry implemented the engine's updated technologies to restrict this compound.

The flame propagation speed of natural gas is a function of the air-fuel ratio. So, providing a homogeneous mixture of air and fuel in the main chamber is extremely crucial. However, a homogenous mixture is not sufficient if it is a lean mixture because the flame will not propagate appropriately with the standard spark plugs. To succeed in this obstacle and granting stable operational conditions, a pre-chamber with local lower lambda is recommended [5]. The flame will propagate into the main chamber after igniting in the pre-chamber enrichment mixture, as shown in Fig. 1. 


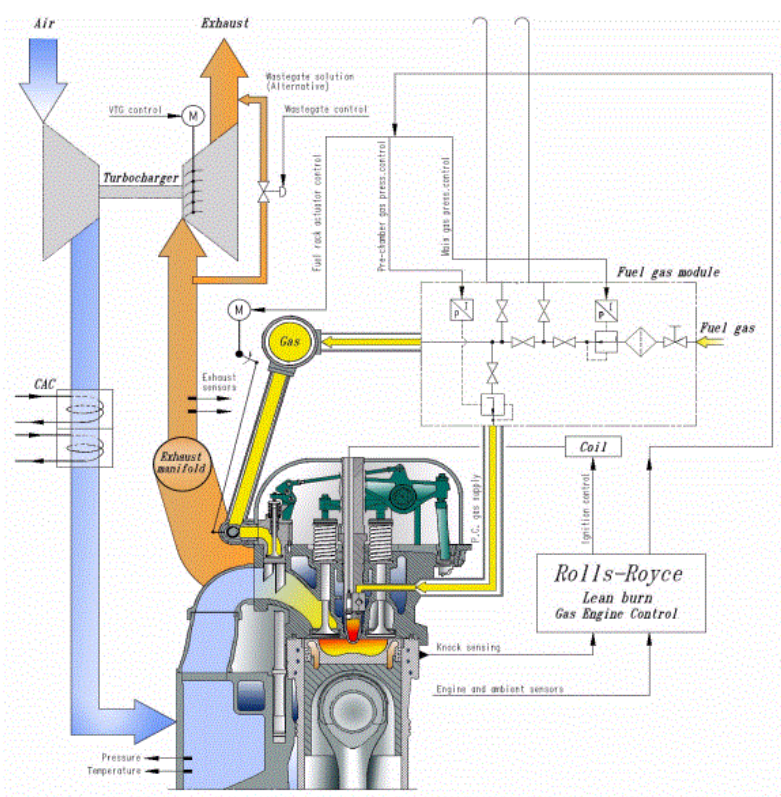

Fig. 1: A pre-chamber installed on top of the main chamber and provides a larger initial flame for starting the main combustion. [7].

In the marine propulsion system, the time-varying wakefield creates fluctuating engine loads, which may differ considerably from the time-invariant engine torque estimated in steady conditions. Providing a stable operational condition gets even worse when the engine torques and the thermal load are low. Supplementary control of the airflow to restrict the extra air improves the flame quality. This additional control is performed in the B35:40 Bergen engine with installing a throttle system for the torque lower than $30 \%$ of the nominal load [7].

The effect of intake throttling has been studied predominantly on the CI and SI engines [8-9]. The intake-throttling device enhanced EGR injection by reducing the pressure behind the intake valve, and it effectively accelerated the natural gas combustion [10]. In contrast, due to the pumping losses caused by partially opened of the throttle in the air passage, the efficiency of the engine decreased during lower loads. Therefore, using early intake valve closure (EIVC) on intake valves was proposed to improve the combustion quality in direct injection gasoline engines. Ojapah et al. [11] developed this idea by testing a single-cylinder engine and concluded that EIVC contributed to combustion efficiency improvement. The drawback was increasing the UHC formation due to slower combustion compared with throttle control.

Returning to the hypothesis posed in this section, this study evaluated the air throttle valve's influence during lower loads in steady-state and transient conditions. To date, this comparison has not been discussed, particularly for the leanburn combustion. In this study, a thermodynamic engine model was built to model a marine gas engine. The engine was simulated with an imposed constant torque for the steady-state condition, and an imposed changeable torque for the transient state. Therefore, in the next section, the modeling procedure is presented, and the primary output is verified with the engine manufacturer's measured data. The imposed loads are presented in section 3, and the importance and essence of the throttle in lower loads are discussed in section 4. The conclusion is expressed in section 5.

\section{Simulation method}

A thermodynamic model was performed by GT-suite 2019 software. This program simulated the dynamic of the inlet and outlet gases, turbocharger performance, and combustion flame characteristics. Depending on the model's type, the simulation could be predictable, semi-predictable, or non-predictable [12]. The thermodynamic process model commenced from the atmosphere with a boundary inlet temperature and pressure of the sea level, and it was continued to the compressor with an implemented performance map or lookup table from the ABB company. The converted 
thermodynamic energy from the mechanical shaft the turbocharger provided a high boost pressure and the inlet air temperature. A charge air cooler received the high-temperature air at the entry, and it delivered the low-temperature air with with some pressure drop. In order to simulate the dynamics of the airflow in the pipes, the equations of momentum were derived together with energy and mass conservation in the discretized volume. To estimate the mass flow rate over the intake intake and exhaust valves, a one-dimensional isotropic flow analysis for compressible flow through a flow restriction was was performed [13]. Combustion was modeled in all the cylinders by implementing the flame propagation model [14], and the emission formation proceeded in the kinetic form with essential species, such as $\mathrm{N}_{2}, \mathrm{O}_{2}, \mathrm{CO}_{2}$. Afterward, the burned gas was passed via the exhaust valves and exhaust ports. The high enthalpy gas of the exhaust carries considerable thermal energy, and it drives the turbine to generate torque to rotate the connecting shaft and compressor. Then, the low enthalpy gas discharges into the atmosphere, and the cycle becomes complete. The specification of the marine engine is presented in Table 1 .

Table 1: Engine specification.

\begin{tabular}{|l|c|c|}
\hline Item & unit & amount \\
\hline Number of cylinders & - & 9 \\
\hline Cylinder bore & $\mathrm{mm}$ & 350 \\
\hline Cylinder stroke & $\mathrm{mm}$ & 400 \\
\hline Connecting rod & $\mathrm{mm}$ & 810 \\
\hline Maximum power & $\mathrm{kW}$ & 3940 \\
\hline Rated speed & $\mathrm{rpm}$ & 750 \\
\hline Maximum Torque at rated speed & $\mathrm{Nm}$ & 50200 \\
\hline Fuel type & - & Natural gas \\
\hline
\end{tabular}

A detail of the implemented equations was presented in work by these authors in [15]. The available measured data such as sea boundary condition, wall temperatures, spark plug locations, and timings were all imposed in the simulation model. A schematic of the engine modeling and the air throttle position is shown in Fig. 2.

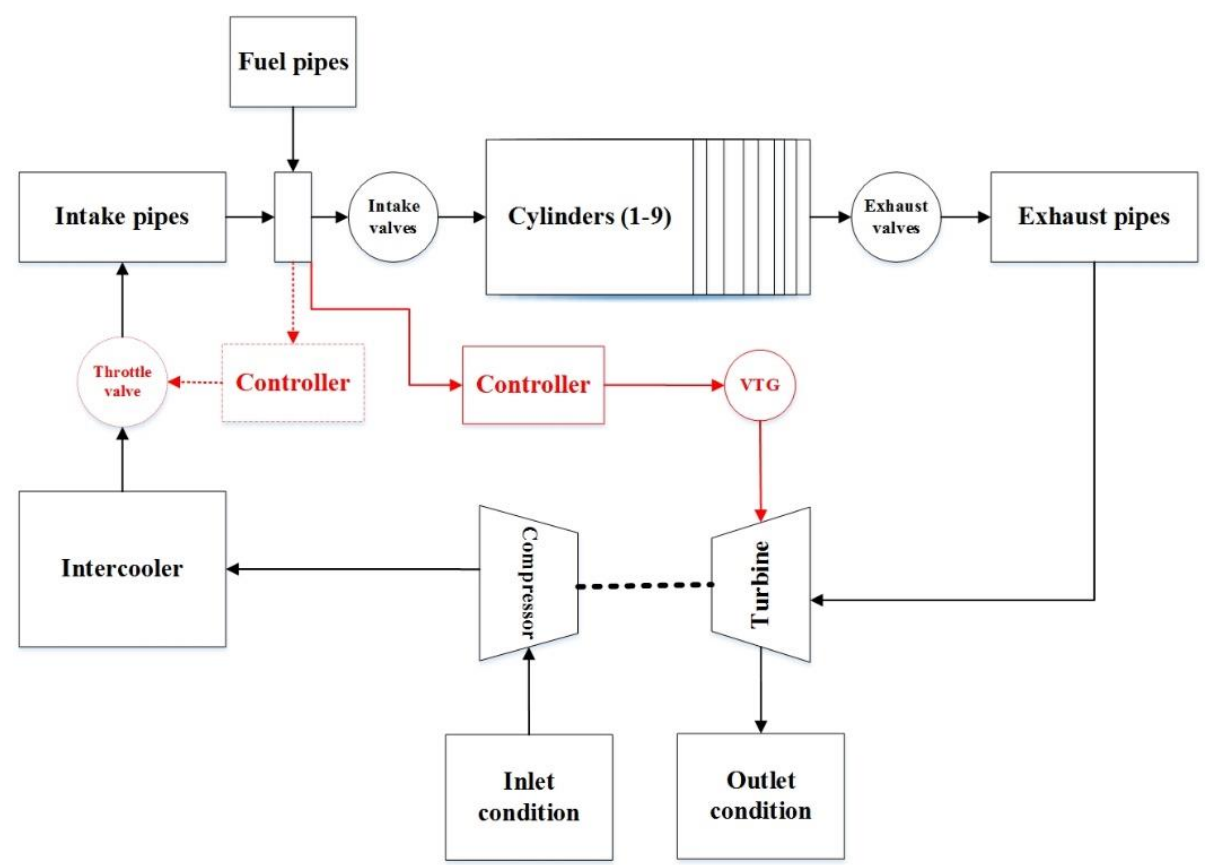

Fig. 2: Decomposition of engine modeling. 
The model is validated both in steady-state and in transient conditions. A comparison between experimental and simulation output verifies that the model could accurately predict the engine performance and emission compounds. presents the validation for a steady-state. Normalized BSFC for performance prediction and normalized UHC for prediction is given. Furthermore, Fig. 3 presented the fuel flow rate in almost 300 seconds of the load variation. This displayed an acceptable agreement of the simulation results with the measured data with time-varying load.

Table 2: Engine model verification during the steady-state with a comparison of measured and simulated data.

\begin{tabular}{|c|c|c|c|c|c|c|}
\hline \multirow{2}{*}{$\begin{array}{c}\text { Load } \\
(\%)\end{array}$} & \multicolumn{3}{|c|}{ BSFC (Normalized) } & \multicolumn{3}{c|}{ UHC (Normalized) } \\
\cline { 2 - 7 } & Measured & Theory & Deviation(\%) & Measured & Theory & Deviation $(\%)$ \\
\hline 100 & 1 & 1 & 0 & 1 & 1 & 0 \\
\hline 85 & 1.029 & 1.018 & 1 & 1.11 & 1.05 & 5.4 \\
\hline 75 & 1.045 & 1.034 & 1 & 1.20 & 1.10 & 8.3 \\
\hline 50 & 1.089 & 1.108 & -1.7 & 1.37 & 1.30 & 5.1 \\
\hline 25 & 1.374 & 1.334 & 2.9 & 2.0 & 2.01 & 0.5 \\
\hline
\end{tabular}

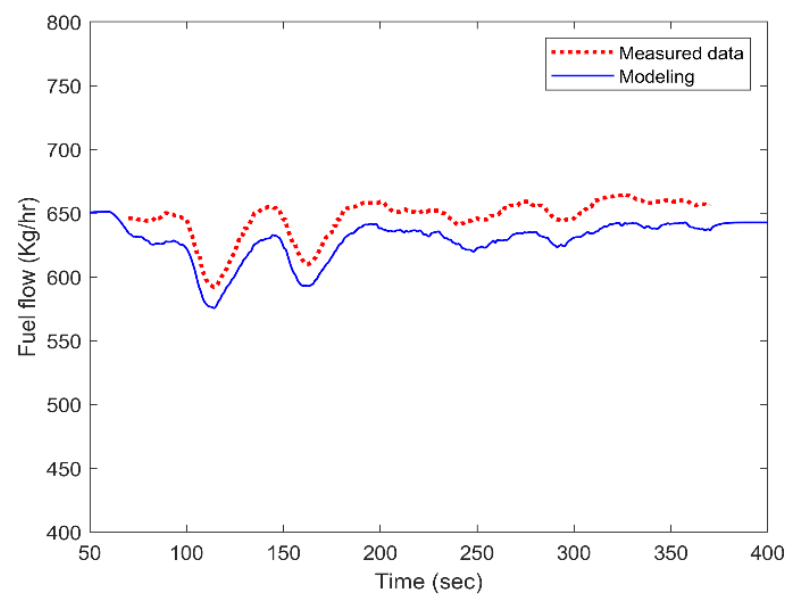

Fig. 3: Fuel flow comparison between measured data and simulated model for verifying the model during the transient condition.

\section{Implemented steady and transient torque}

In order to evaluate the significance of throttle in the lower loads of a lean-burn spark-ignition gas engine, two operating loads were studied, steady-state and unsteady state.

For the steady-state condition, the implemented load reduced from $100 \%$ to $50 \%, 25 \%, 20 \%, 15 \%, 10 \%$ and $5 \%$. $100 \%$ and $50 \%$ mean almost 50000 and $25000 \mathrm{Nm}$, and the engine is regulated with the standard variable turbine geometry (VTG) controller. In the $25 \%$ load and less, which are $12500 \mathrm{Nm}$ and less, the throttle regulated the amount of airflow. The throttle controller consisted of a conventional PID controller with two sensors form air and fuel pipes to calculate the ratio and one actuator to change the throttle valve degree between 0 to 90 .

An identical controlling pattern of VTG and throttle was utilized for the transient condition. The estimated harmonic load against harsh weather conditions is shown in Fig. 4. A ship traveling in various wavelengths, wave amplitudes, and wave directions influences the wave size and changes the thrust and torque fluctuations. More detail of the wave's calculation was presented in the work of Saettone et al. [16]. This wave amplitude and frequency satisfied our requirement for modeling the marine engine in a broad spectrum of loading. The load changed from a constant value of $36000 \mathrm{Nm}$ in the second 180 to almost $45000 \mathrm{Nm}$ and then reduced to zero. The wave period was nearly seven seconds, which has around four seconds for the higher loads, and fewer than three seconds for the loads less than $30 \%$, the duration when the throttle is active. 


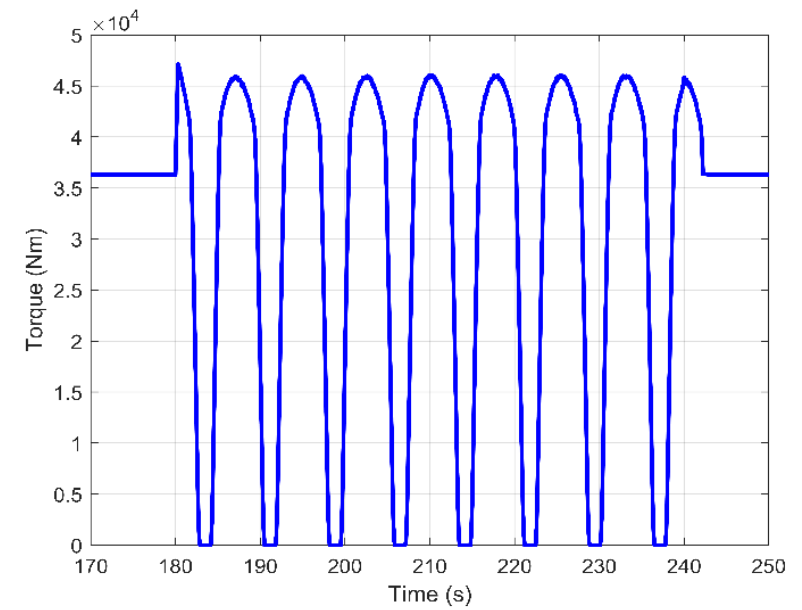

Fig. 4: Implemented dynamic loading calculated by a wave amplitude of two meters[16].

\section{Results and Discussion}

In order to compare the results, the nominal engine speed of $750 \mathrm{rpm}$ was chosen. The engine speed operated around the constant value by adjusting the fuel rack position with a PID controller. The measured data and simulation results confirmed that the engine had satisfying stability around the speed setpoint [17]. The results of this section are divided into two groups: Performance output and emission formation. Fig. 5 illustrated the air-fuel ratio comparison in a steady-state with and without throttle. A target setpoint, which is a constant quantity of 31 , was also shown. As can be seen, during steady-state with a throttle, the air-fuel ratio stayed equal to the setpoint. However, there was an exception with the $25 \%$ load. This deviation may stem from numerical error and is negligible. While without the throttle, the ratio grew up to 34 during lower loads. This ratio is extremely lean for stable combustion, and it results in quenching the flame. Fig. 6 shows that the combustion efficiency reduces during the lower load if there was no throttle on the air passage. Besides, with the throttle, combustion efficiency lingered almost constant during load variation since the air-fuel ratio was consistent. In contrast, Fig. 7 shows that using the throttle during the transient load was not adequate for regulating the amount of air, as indicated by a circle. Therefore, the excess ratio always exceeded the setpoint with or without throttle. The combustion efficiency also shows the same pattern, as shown in Fig. 8. Referring to the frequency of the waves in Fig. 4 and based on the results, we can conclude that this small time scale is extremely short for the throttle to turn into convergence. Therefore, for such high-frequency waves, a device with a more rapid response is needed to provide acceptable stability.

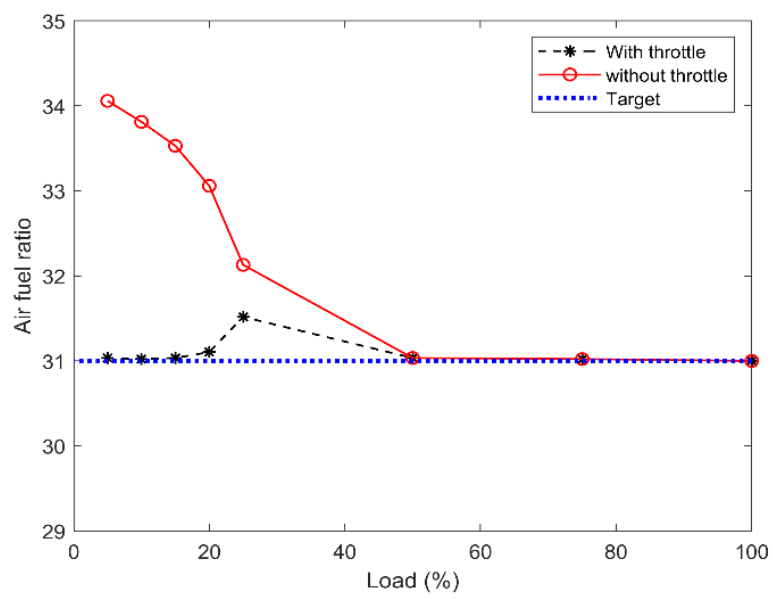

Fig. 5: Air fuel ratio variation during steady-state. 


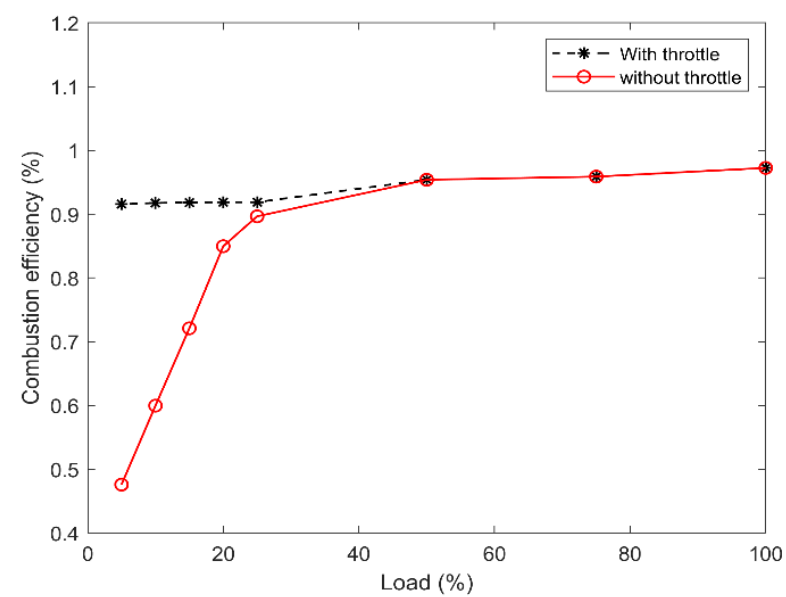

Fig. 6: Combustion efficiency during steady-state.

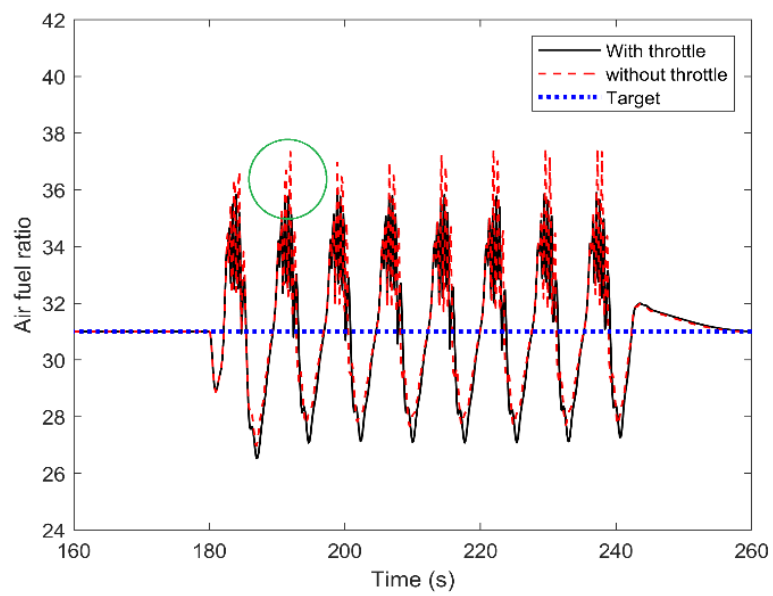

Fig. 7: Air fuel ratio variation during transient condition.

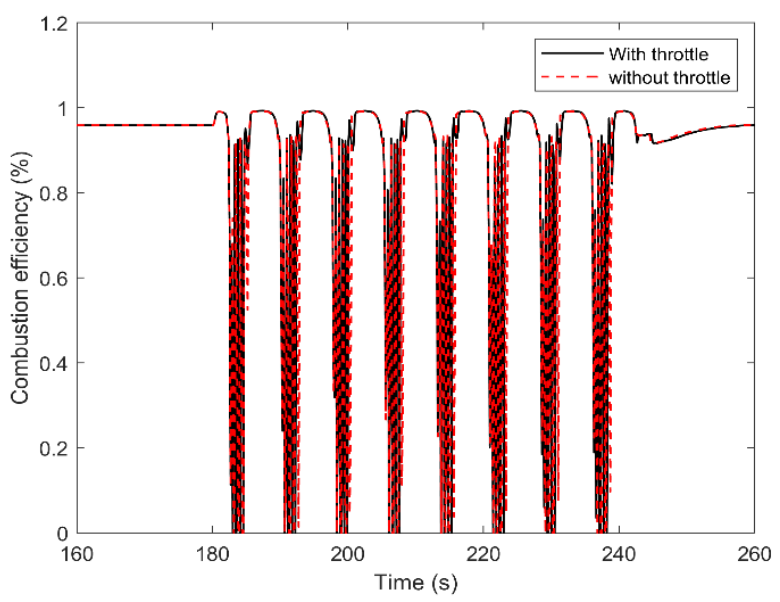

Fig. 8: Comparison of combustion efficiency in the engine with and without throttle during transient condition. 
Two other figures for the engine performance, Fig. 9 and Fig. 10, also signified the importance of using throttle for the airflow control during the lower loads. The quantity in the $100 \%$ load was employed to normalize these figures' numbers. Without considering a throttle during the stable working condition, as shown in Fig. 9, the fuel consumption increased drastically with the loads below $20 \%$ and almost doubled by $5 \%$. The brake specific fuel consumption during the transient loading was also shown by Fig. 10. A zero combustion efficiency resulted in an infinite quantity for BSFC in the calculation. Therefore, the graph for BSFC in the transient condition was limited to a maximum of seven times more than nominal BSFC. The figures again showed the persistence of insignificance of the throttle in transient conditions during high load variation.

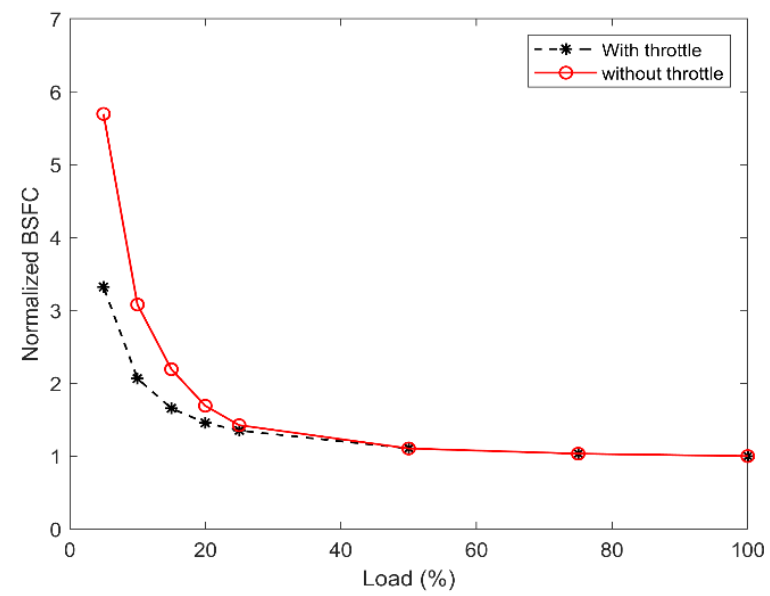

Fig. 9: Normalized brake specific fuel consumption during steady-state.

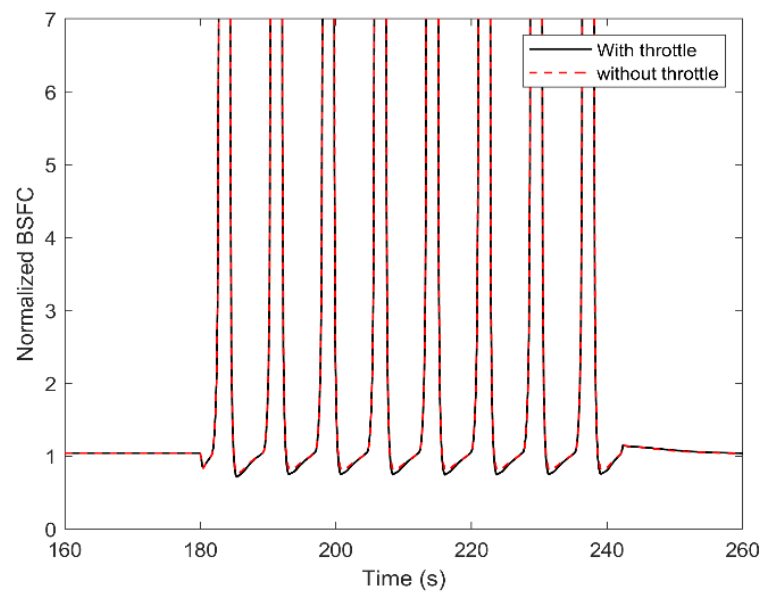

Fig. 10: Normalized brake specific fuel consumption with transient loading.

The data obtained for the emission formation are broadly consistent with the performance output's major trends. Fig. 11 and Fig. 12 displayed the variation of unburned hydrocarbon in these two operational modes, with and without throttle. These authors' previous work [17] revealed that the UHC compound directly correlates with the air-fuel ratio, and a higher amount of excess air ratio deteriorated the combustion quality and resulted in the flame quench. Besides, flame quench was one of the three primary UHC sources in lean-burn spark-ignition gas engines together with gas exchange and crevice volume. Therefore, a significant part of the fuel remained unburned when the excess ratio increased to a value more than the setpoint. When the load declines, the fraction of unburned fuel will increase as well. As shown in Table 2, the measure data proved 
that the UHC quantity in $25 \%$ load is doubled compared with $100 \%$ load, and following the same trend in Fig. 11 shows seven times UHC increases with a 5\% load when the engine is working in steady-state and with the throttle. Skipping throttle may increase the UHC up to 80 times higher value. This amount of unburned fuel results in almost twice fuel consumption during the lower loads. Hence, the significance of using a throttle during lower loads can be proved in the emission aspect as well, even though it is not beneficial in transient conditions, as shown in Fig. 12.

Furthermore, $\mathrm{NO}_{\mathrm{X}}$ showed a contrast procedure compared with the UHC compound, as shown in Fig. 13 and Fig. 14. This emission compound is deeply relevant to the flame temperature [13]. With a higher air-fuel ratio, the combustion chamber's thermal load declined, and the amount of $\mathrm{NO}_{\mathrm{X}}$ reduced. It worth mentioning that in Fig. 13, there is a sudden reduction for the $25 \%$ load for the engine output with a throttle. Part of this reduction of $\mathrm{NO}_{\mathrm{X}}$ stems from the unexpected higher air-fuel ratio, as was mentioned in Fig. 5.

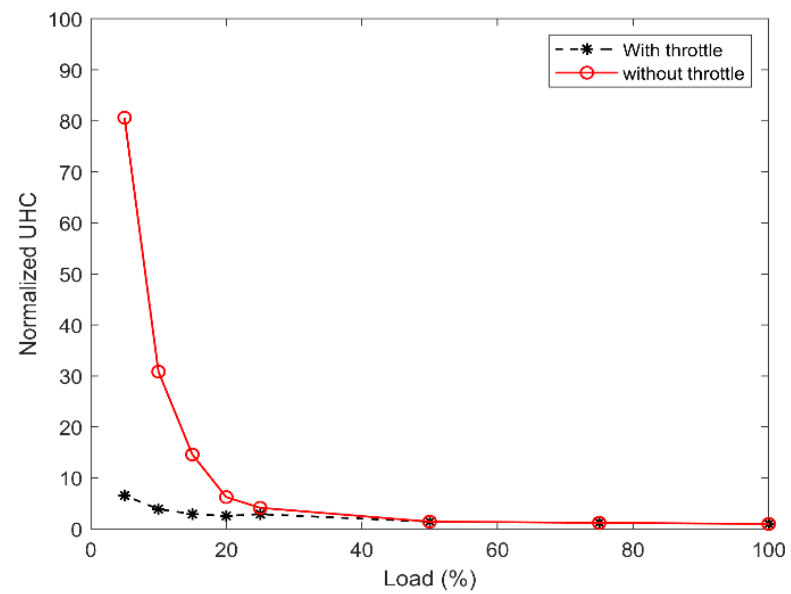

Fig. 11: Normalized unburned hydrocarbon formation during the steady-state.

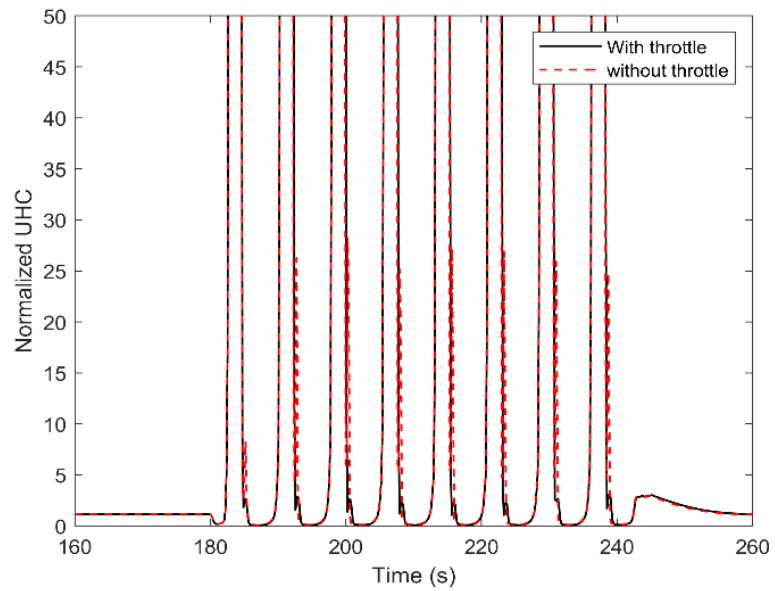

Fig. 12: Normalized unburned hydrocarbon formation during the transient condition. 


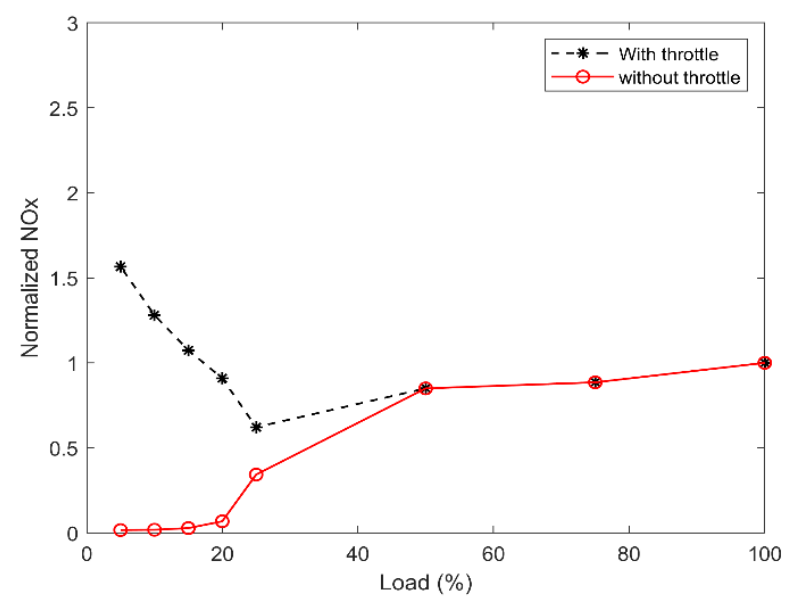

Fig. 13: NOx formation during steady state.

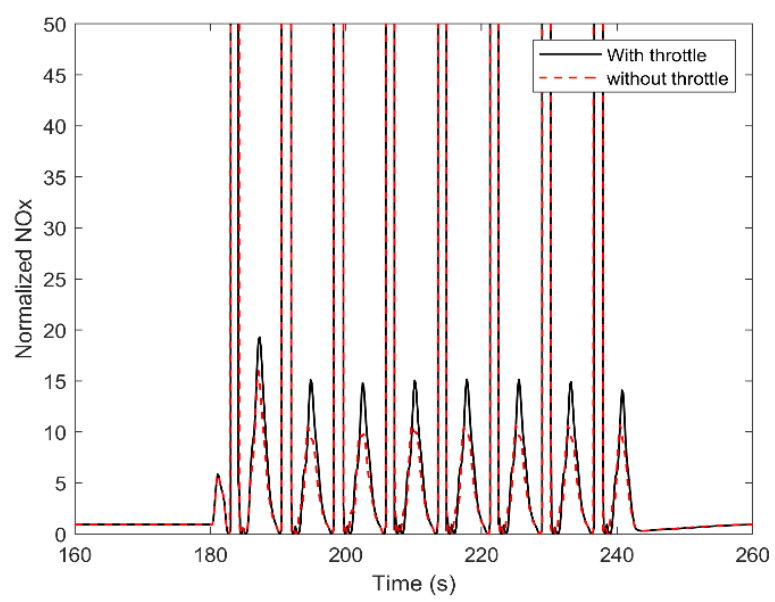

Fig. 14: NOx formation during transient condition.

\section{Conclusion}

This work emphasized the engine performance, i.e., the dynamic response, combustion efficiency, and emission resulting from the constant load and oscillating propeller load. There was a particular interest in examining the throttle adjustment on the engine performance of lean-burn combustion. A thermodynamic spark-ignition engine model was developed, and the results revealed that the engine was effectively regulated with the throttle during lower loads of the steadystate. The fuel consumption and the emission formation are exceptionally determined by the throttle, and uninstalling the throttle valve results in incomplete combustion and lots of unburned hydrocarbons.

Based on the findings presented in this paper for the transient condition when the frequency is high, the throttle did not recover the engine's characteristics during lower loads. It was shown that the time scale of the throttle angle for the newly adjusted setpoint was longer than the waves' period. The created delay in providing the new throttle angle restricted a rapid response by the engine, especially in harsh weather conditions. Therefore, the application of the throttle valve in the fasttransient state is worthless. 


\section{References}

[1] J. Rogelj, M. den Elzen, N. H“ohne, T. Fransen, H. Fekete, H. Winkler, R. Schaeffer, F. Sha, K. Riahi, and M. Meinshausen, "Paris agreement climate proposals need a boost to keep warming well below 2c," Nature, no. 18307, 2016.

[2] E. Fridell, E. Steen, and K. Peterson, "Primary particles in ship emissions," Atmospheric Environment, vol. 42, no. 6, pp. 1160 - 1168, 2008. [Online]. Available: http://www.sciencedirect.com/science/article/pii/S1352231007009648

[3] V. Matthias, I. Bewersdorff, A. Aulinger, and M. Quante, "The contribution of ship emissions to air pollution in the north sea regions," Environmental Pollution, vol. 158, no. 6, pp. 2241 - 2250, 2010, advances of air pollution science: from forest decline to multiple-stress effects on forest ecosystem services. [Online]. Available: http://www.sciencedirect.com/science/article/pii/S0269749110000746.

[4] S. Ushakov, D. Stenersen, and P. M. Einang, "Methane slip from gas fuelledships: a comprehensive summary based on measurement data,'Journal of MarineScience and Technology, vol. 24, no. 4, pp. 1308-1325, 2019.

[5] D. Stenersen and O. Thonstad, "Ghg and nox emissions from gas fuelled engines: Mapping, verification, reduction technologies,” SINTEF Ocean AS, NO-7465 Trondheim NORWAY, Tech. Rep. OC2017 F-108, 2017.

[6] T. I. P. on Climate Change, "Global warming potential values," 2016, iPCC Fifth Assessment Report. [Online]. Available: https://www.ipcc.ch/

[7] "Project guide: Bergen engine type b, fuel gas operation," Bergen Engines AS, Tech. Rep., 2018.

[8] J. Reß, C. St"urzebecher, C. Bohn, F. M"arzke, and R. Frase, "A diesel engine model including exhaust flap, intake throttle, lp-egr and vgt. part i: System modeling," IFAC-PapersOnLine, vol. 48, no. 15, pp. 52 - 59, 2015, 4th IFAC Workshop on Engine and Powertrain Control, Simulation and Modeling E-COSM 2015. [Online]. Available: http://www.sciencedirect.com/science/article/pii/S2405896315018844

[9] V. B. Pedrozo, I. May, T. D. Lanzanova, and H. Zhao, "Potential of internal egr and throttled operation for low load extension of ethanol-diesel dual-fuel reactivity controlled compression ignition combustion on a heavy-duty engine," Fuel, vol. 179, pp. 391 - 405, 2016. [Online]. Available: http://www.sciencedirect.com/science/article/pii/S0016236116301326.

[10] J. You, Z. Liu, Z. Wang, D. Wang, Y. Xu, G. Du, and X. Fu, "The exhausted gas recirculation improved brake thermal efficiency and combustion characteristics under different intake throttling conditions of a diesel/natural gas dual fuel engine at low loads," Fuel, vol. 266, p. 117035, 2020. [Online]. Available:

http://www.sciencedirect.com/science/article/pii/S0016236120300302

[11] M. Ojapah, Y. Zhang, and H. Zhao, "Part-load performance and emissions analysis of si combustion with eivc and throttled operation and cai combustion," in Internal Combustion Engines: Performance, Fuel Economy and Emissions. Woodhead Publishing, 2013, pp. 19 - 32. [Online]. Available: http://www.sciencedirect.com/science/article/pii/B9781782421832500020

[12] GT-SUITE, "Flow theory manual," Gamma Technologies, Tech. Rep., 2017.

[13] J. B.Heywood, Internal Combustion Engines Fundemental. New York: McGraw-Hill, Inc, 1988.

[14] N. C. Blizard and J. C. Keck, "Experimental and theoretical investigation of turbulent burning model for internal combustion engine," SAE, p. 740191, 1974.

[15] S. Tavakoli, E. Pedersen, and J. Schramm, "Natural gas engine thermodynamic modeling concerning offshore dynamic condition," Proceedings of the 14th International Symposium, PRADS 2019, September 22-26, 2019, Yokohama, Japan, vol. II, 2019.

[16] S. Saettonea, B. Taskara, P. B. Regenera, S. Steen, and P. Andersena, "A comparison between fully-unsteady and quasisteady approach for the prediction of the propeller performance in waves," Applied Ocean Research, vol. 97, 2019.

[17] S. Tavakoli, M. V. Jensen, E. Pedersen, and J. Schramm, "Unburned hydrocarbonformation in a natural gas engine under sea wave load conditions,"Journal ofMarine Science and Technology, 2020. 